\title{
Research on Misunderstandings of "Cross-cultural Theories" and Strategies of Cultural Security in College English Teaching
}

\author{
Danke Zhang \\ Chongqing Nanfang Translators College of SISU, Chongqing, 401120, China
}

Keywords: college English teaching; cross-cultural theories; misunderstanding; cultural security

\begin{abstract}
Language can be regarded as an important bridge for culture. Given the rapid development of current networks and new media technologies, cultural exchanges between China and the West have become more frequent. As an organic part of English teaching, the cross-cultural theories are becoming increasingly important in teaching. Meanwhile, some of bad social thoughts in Western culture have infiltrated into college campuses through multiple channels, leaving a great impact on the values of contemporary college students. Therefore, it is necessary to start with cross-cultural theories and thoroughly explore strategies of cultural security in college English teaching under the new situation. This paper elaborates the necessity of improving intercultural communicative competence in college English teaching, analyzes the misunderstandings of "cross-cultural theories" in college English teaching, and puts forward some strategies for strengthening cultural security construction in college English teaching.
\end{abstract}

\section{Introduction}

Because of the intensified trend of world economic integration, cultural diversity becomes more and more common among the interaction of different cultures. Whenever there is a Christmas, Thanksgiving or other Western festivals, the atmosphere is no less than that of the Spring Festival in China. Foreign-owned enterprises such as KFC and McDonald's are also very popular in China. Although the cheongsam representing traditional Chinese culture is elegant and graceful, few people wear it. Instead, they are dressed in exotic costumes from the West. These have affected college campuses. At present, some college students have blindly worshipped or even followed the cultures of other countries, which have seriously impacted the spread of Chinese traditional culture. It can be seen that the cultural security of our country is being severely challenged. Here, the author will study strategies of cultural security in English teaching, from the perspective of cross-cultural theories.

\section{The Necessity of Improving Intercultural Communication Ability in College English Teaching}

The first request is made according to cultural differences in different countries. Different countries and different languages have their own distinct characteristics. Even in different countries where the same language is used, there will be considerable differences in specific use. In particular, English is a foreign language for college students in our country, and is often very difficult to learn and use. Therefore, in college English classroom teaching, teachers must attach great importance to cultural differences and focus on building the cross-cultural communication ability of college students, so that students can better cope with the future of social development, and thus become talents with cross-cultural communication skills that the current society needs.

The second request is made to improve college students' English communication skills. When college students communicate with each other in English, they don't simply use literal meaning and subjective awareness to carry out translation work. Only on the premise of understanding relevant cultures can they better use English knowledge to communicate with others. In foreign exchanges, we must fully respect the cultures of other countries, which will not only directly affect the economic and trade exchanges between different countries, but the national image and market competitiveness. 
Therefore, it is necessary for college students to have a richer theoretical knowledge of cultures in order to better communicate in English.

\section{Misunderstandings of "Cross-Cultural Theories" in College English Teaching}

The first misunderstanding: Failure to be well aware of the negative effects of bad cultural invasions from the West. Language and culture cannot be divided, so the cultures of various aspects of relevant English-speaking countries are introduced in high school English teaching based on the teaching of English language knowledge, mainly covering aspects of politics, economy, national conditions, and customs of these countries, among which there are positive and progressive values and novel and interesting cultural traditions that are worthy of learning, there are unavoidable negative aspects such as extravagant enjoyment, money worship and individualism. The above Western cultural trends have greatly impacted the current values of the undergraduate group in the post-95 generation, allowing them to gradually show problems such as westernization in their life habits, focusing on foreign festivals and distortion of values.

The second misunderstanding: Failure to integrate excellent Chinese traditional culture in English teaching. Different from the fact that the western culture has become popular in the campus of our country, our traditional culture has no place in college English teaching. Some researchers have once argued that the college English teaching in China only focuses on introducing the material, institutional, customary, and spiritual and cultural aspects of English-speaking countries, while the English language expression of the Chinese cultural background, one of the cross-cultural communicative subjects, has always been ignored. In college English classes in China at present, teachers are restricted by the teaching hours, class sizes and their own cultural qualities, etc. In the process of English teaching, English language and Western culture are generally considered as the main teaching content. However, a considerable number of teachers have imbued Western cultures into students without a scientific and rational analysis and judgment. On the other hand, they rarely teach content related to China's excellent traditional culture. According to a survey, the current Chinese college students know very little about the sources of traditional Chinese festivals such as Lantern Festival, Ching Ming Festival and Dragon Boat Festival, etc.

The third misunderstanding: Failure to cultivate college English teachers' own awareness of cultural safety. The problem that our country's college English educators and college students need to solve is how to maintain cultural security based on the group education of college students, so that they can form a stronger sense of cultural security and achieve better development. In order to effectively maintain the cultural security of our country, College English teachers need to be aware of the important value and urgency of maintaining national security. Teachers' outlook on life and values will be transmitted to students, because they are not only the managers but also the executors of higher education. Only when teachers can keep remembering the important value of cultural security education can they incorporate the content of cultural security education into the daily teaching. Only if teachers themselves practice the traditional Chinese culture and have a strong sense of cultural security and national pride can students truly feel the distinctive culture of our nation, which makes cultural education more appealing. At the same time, in terms of professional knowledge, English teachers should continue to learn the Chinese traditional culture and find more ideal cultural teaching methods in the work process.

Colleges and universities have always occupied a very important position in the modern society, and play an extremely important role in cultural exchanges and communication, so the issue of campus cultural security should receive greater attention. Therefore, as an important window for college students to get to know western cultures, college English teaching is of great value in guiding the student population to resist the intrusion of bad thoughts in western countries and to promote traditional Chinese culture and safeguard China's cultural security. 


\section{Strategies to Strengthen the Construction of Cultural Security in College English Teaching}

The first is to vigorously upgrade the ideological and political qualities, especially cultural security awareness, of college English teachers. Influenced by the concept of exam-oriented education, the teaching conditions and many other factors, it is common for the teaching staff in colleges and universities to place too much emphasis on professional knowledge and scientific research ability while ignoring the ideological and political qualities. Cultural security is often ignored, disregarded, or even treated as a completely new concept by many college English teachers. It has become a very important task to improve the ideological and political qualities and professional ethics of college English teachers and focus on strengthening cultural safety education in college English classroom teaching. College English teachers must firmly establish the awareness of cultural security, eliminate the outdated notion that the teaching of Chinese traditional culture is entirely the responsibility of Chinese teachers and continuously improve their own sense of responsibility. In the classroom teaching activities, they should consciously promote the core values, regard themselves as important behavioral norms and judgment standards, and use teachers' personality charm and example effects to influence college students.

The second is to actively improve teaching methods to improve college students' critical thinking ability. Traditionally, college English teaching tends to make students passively accept all kinds of knowledge, without paying attention to improving students' enthusiasm, leading them to jointly explore unknown knowledge, or and in-depth analysis of problems and solutions to problems. With the continuous advancement of college English teaching reform, university teachers should fully respect the subjective status of undergraduate students in English learning, carefully design specific courses, and continuously strengthen the cultivation of students' autonomous learning ability. As for cultural teaching, they can fully draw lessons from Heinz's dilemma teaching theory, that is, to apply conflict communication or carry out group discussion on the topic of ethical dilemmas, so as to create cognitive imbalances among college students and further guide them to continuously improve their moral judgment by constantly seeking to find new cognitive balances. English teachers can start from a certain cultural phenomenon and use group discussion to organize debates in groups so as to guide students to more comprehensively analyze the essential characteristics of various cultural phenomena and to create their own independent and objective cognition for Western cultures. At the same time, college students should also be actively encouraged to share their cognitive results through classroom reporting. It is necessary to carry out discussions and evaluations from multiple perspectives in a planned way so that college students' learning ability can be further developed and their critical thinking ability can be improved. As a result, the Western cultural knowledge involved in English teaching will no longer be blindly worshipped, but treated more dialectically.

The third is to improve cultural confidence in the comparison of Chinese and Western cultures. While studying English, college students in our country must comprehensively re-examine the splendid Chinese traditional culture that is being ignored, and fully understand and inherit the achievements of civilization created by the Chinese nation in the long history. What is uplifting is that English textbooks in some universities have begun to pay more attention to traditional Chinese culture, especially the comparison of Chinese and Western cultures. For example, the comparison of Chinese and Western name cultures can be introduced in teaching. Through the comparison of two different name structures, students can better grasp the different meanings of "family name" and "given name", so as to understand the relationship between first name and last name in English culture and surname and name in Chinese culture. Based on the comparison of the Chinese and Western names, college students can also fully understand the difference between the phonetic characters in English and the ideographic characters in Chinese, and realize that the Chinese language is profound and inspiring, which inspires the students' initiative in learning, improves their national self-confidence and their sense of responsibility for maintaining cultural security. 


\section{Conclusion}

In short, at the moment when the trend of world integration is becoming more and more significant, the cultivation of college students' communicative competence in English teaching under the guidance of cross-cultural theories has a very important value, and has become one of the important goals of college English classroom teaching. In order to further improve the English ability of college students and adapt them to the current environment, English teachers should use a variety of teaching methods so that students can learn cultures in a relaxing and pleasant atmosphere. Good language learning situations are created for college students, so as to guide students to pay more attention to cultural security issues. As the forefront of the spread of Western culture to China, the issue of cultural safety in colleges deserves greater attention. College English teachers should carefully guide students to inquire into Western cultural issues. In the process of college English teaching, teachers should introduce the excellent traditional culture of our country, in order to improve the sense of pride in the Chinese traditional culture of the college students and lay a solid foundation for their better involvement in international exchanges in the future.

\section{Acknowledgement}

Research on English Education and Cultural Security in the Visual Threshold of Intercultural Communication.

\section{References}

[1] Wang Ning, Sun Wei. On Mother Tongue and Its Security, Journal of Shaanxi Normal University (Philosophy and Social Science Edition), 2005 (6).

[2] Wu Susu, Zhang Shuqin. A New Understanding of College English Grammar Teaching under the New Situation, Educational Exploration, 2010(4).

[3] Dai Manchun. National Language Ability, Language Planning and National Security, Applied Linguistic, 2011(4).

[4] Ye Xiaojun. Breakthrough of Foreign Language Teaching and Culture in Tibetan Students' English Learning, Journal of Beijing Institute of Education, 2013(4).

[5] Yu Lei. Study on Strategies of Communicative Competence in College English Teaching, Education Science and Culture, 2013(10). 